\title{
Mental Health of Medical Workers in Japan during COVID-19: Relationships with Loneliness, Hope and Self-Compassion
}

Yasuhiro Kotera ( $\nabla$ yasuhirokotera@gmail.com )

University of Derby https://orcid.org/0000-0002-0251-0085

Akihoko Ozaki

University of Derby

Hirotomo Miyatake

University of Derby

Chie Tsunetoshi

University of Derby

Yoshitaka Nishikawa

University of Derby

Tetsuya Tanimoto

University of Derby

\section{Short Report}

Keywords: Japan, medical workers, mental health, loneliness, COVID-19

Posted Date: October 13th, 2020

DOI: https://doi.org/10.21203/rs.3.rs-91467/v1

License: (1) This work is licensed under a Creative Commons Attribution 4.0 International License.

Read Full License

Version of Record: A version of this preprint was published at Current Psychology on February 20th, 2021. See the published version at https://doi.org/10.1007/s12144-021-01514-z. 


\section{Preprint}

Mental Health of Medical Workers in Japan during COVID-19: Relationships with Loneliness, Hope and Self-Compassion.

\section{Citation}

Kotera, Y., Ozaki, A., Miyatake, H., Tsunetoshi' C., Nishikawa, Y.\& Tanimoto, T. (2020). Mental health of medical workers in japan during covid-19: Relationships with loneliness, hope and self-compassion. Preprint.

Conflicts of interest: No conflicts of interested to be noted. 


\begin{abstract}
The current pandemic of the coronavirus disease 2019 (COVID-19) has negatively impacted medical workers' mental health in many countries including Japan. Although research identified poor mental health of medical workers in COVID-19, protective factors for their mental health remain to be appraised. Accordingly, this study aimed to investigate relationships between mental health problems, loneliness, hope and self-compassion among Japanese medical workers, and compare with the general population. Online self-report measures regarding those four constructs were completed by 142 medical workers and 138 individuals in the general population. T-tests and multiple regression analysis were performed. Medical workers had higher levels of mental health problems and loneliness, and lower levels of hope and self-compassion than the general population. Loneliness was the strongest predictor of mental health problems in the medical workers. Findings suggest that Japanese medical workplaces may benefit from targeting workplace loneliness to protect staff mental health from the current crisis.
\end{abstract}

Keywords: Japan; medical workers; mental health; loneliness; COVID-19 


\section{Introduction}

Poor psychological status among medical workers can limit the quality and quantity of the medical workforce, leading to poor clinical outcomes. This is particularly relevant to the current pandemic of the novel coronavirus disease 2019 (COVID-19), as it can cause negative impacts on mental health of medical workers (Matsuo et al., 2020; Moreno et al., 2020; Spoorthy, 2020). Considering strong stigma attached to mental illnesses among Japanese medical professionals (Ando et al., 2013), directly engaging with mental health problems may not be effective as it can stimulate their stigma (AUTHOR, 2020). Previous studies elucidated the prevalence and levels of mental distress in medical workers during COVID-19 (Matsuo et al., 2020; Moreno et al., 2020; Spoorthy, 2020), however protective factors for their mental health were not evaluated. Healthful factors of mental health need to be appraised to identify effective interventions (Choi et al., 2020). Accordingly, we examined the relationships between mental health problems (depression and anxiety), loneliness (feeling alienated from others; Sekhon \& Srivastava, 2019), hope (positive motivational construct, helpful during a crisis; Bernardo \& Mendoza, 2020), and self-compassion (kindness towards oneself, associated with wellbeing; Sinclair et al., 2017) during the COVID-19 pandemic in medical workers in Japan.

\section{Methods}

We aimed to contextualise the psychological status of medical workers by comparing with that of the general population in Japan. Online survey was distributed to Facebook groups formed by medical workers and the general population in June 2020, to which opportunity samples of 160 medical workers and 164 individuals in the general population agreed to participate. Participants had to (i) be 18 years old or older, (ii) be living in Japan at the time of the study, and (iii) have at least three years of experience living in Japan. To 
reduce the workload of participants, following four short scales were included in the survey: The Patient Health Questionnaire-4 (Löwe et al., 2010), Three-Item Loneliness Scale (Hughes et al., 2004), Adult State Hope Scale (Snyder et al., 1996), and Self-Compassion Scale-Short Form (Raes et al., 2011). Of the agreed participants, 142 medical workers (28 doctors, 34 nurses, 29 pharmacists, 27 rehabilitation workers, and the remaining 24 included social workers and radiographers) and 138 individuals from the general population (85 fulltime employees, 29 self-employed workers, 11 part-timers, and the remaining 13 included unemployed and homemakers) completed the survey. Both groups satisfied the required sample size per power calculation (119: Effect size $\mathrm{f}^{2}=0.15, \alpha=0.05$, Power $=0.95$; (Faul et al., 2009). Once data was screened for outliers and normalities, t-tests and multiple regression analysis were conducted. Ethical approval was obtained from the university research ethics committee. This study followed the Strengthening the Reporting of Observational Studies in Epidemiology (STROBE) reporting guideline.

\section{Results}

Our t-tests revealed that medical workers had high levels of mental health problems ( $p$ $=0.004, t=2.88)$ and loneliness $(p=0.043, t=2.04)$, and low levels of hope $(p=0.010, t=-$ 2.62) and self-compassion ( $p=0.004, t=-2.89)$, relative to the general population.

[Please insert Table 1 here]

In multiple regression, first, gender and age were entered to adjust for their effects (Step 1), then, loneliness, hope and self-compassion scores were entered (Step 2). Multicollinearity was of no concern (VIFs $<10)$. Loneliness $(p<0.001, \beta=0.39)$, hope $(p<$ $0.001, \beta=-0.28)$ and self-compassion $(p=0.007, \beta=-0.22)$ were significant predictors of mental health problems in medical workers, where loneliness was the strongest, and selfcompassion was the weakest predictor; whereas hope was the strongest in the general 
population $(p=0.003, \beta=-0.27$ ) (Table 1$)$. The three predictors predicted a greater variance of mental health problems in medical workers than in the general population $(44 \%>30 \%)$.

[Please insert Table 2 here]

\section{Discussion}

During the COVID-19 pandemic in Japan, our analyses identified (i) poor mental health and weakened psychological resources of medical staff, and (ii) the importance of loneliness, hope and self-compassion to their mental health, particularly the strongest impact of loneliness. These findings suggest that the medical workforce in Japan can benefit from targeting loneliness in the workplace. As increasingly uncovered in occupational psychology, workplace loneliness is associated with limited job performance (Ozcelik \& Barsade, 2018). Among the loneliness interventions, re-appraising maladaptive social cognitions of lonelier workers, conducted regularly, was found most effective (Masi et al., 2011), translating selfcriticism into self-compassion. A caution is required as a concept of loneliness differs between individualistic and collective cultures, and these studies were primarily conducted in the Western individualistic contexts, different from the Japanese collectivism (Heu et al., 2019). Still, our findings would help identify practical interventions to be employed by Japanese medical teams during COVID-19. As the second wave has begun to arrive in Japan in July 2020 (Noguchi et al., 2020), Japanese medical workers need to protect their mental health to continue to offer quality care for ever-increasing patients suffering from this fatal disease. 


\section{References}

Ando, S., Yamaguchi, S., Aoki, Y., \& Thornicroft, G. (2013). Review of mental-healthrelated stigma in Japan. Psychiatry and Clinical Neurosciences, 67(7), 471-482. https://doi.org/10.1111/pcn.12086

Bernardo, A. B. I., \& Mendoza, N. B. (2020). Measuring hope during the COVID-19 outbreak in the Philippines: development and validation of the state locus-of-Hope scale short form in Filipino. Current Psychology, 1-10. https://doi.org/10.1007/s12144-02000887-X

Choi, K. W., Ph, D., Stein, M. B., Nishimi, K. M., Ph, D., Ge, T., Ph, D., Coleman, J. R. I., \& Ph, D. (2020). An exposure-wide and mendelian randomization approach to identifying modifiable factors for the prevention of depression. 8, 1-11. https://doi.org/10.1176/appi.ajp.2020.19111158

Faul, F., Erdfelder, E., Buchner, A., \& Lang, A.-G. (2009). Statistical power analyses using G*Power 3.1: Tests for correlation and regression analyses. Behavior Research Methods, 41(4), 1149-1160. https://doi.org/10.3758/BRM.41.4.1149

Heu, L. C., van Zomeren, M., \& Hansen, N. (2019). Lonely alone or lonely together? A cultural-psychological examination of individualism-collectivism and loneliness in five European countries. Personality and Social Psychology Bulletin, 45(5), 780-793. https://doi.org/10.1177/0146167218796793

Hughes, M. E., Waite, L. J., Hawkley, L. C., \& Cacioppo, J. T. (2004). A short scale for measuring loneliness in large surveys: Results from two population-based studies. Research on Aging, 26(6), 655-672. https://doi.org/10.1177/0164027504268574

Löwe, B., Wahl, I., Rose, M., Spitzer, C., Glaesmer, H., Wingenfeld, K., Schneider, A., \& Brähler, E. (2010). A 4-item measure of depression and anxiety: Validation and standardization of the Patient Health Questionnaire-4 (PHQ-4) in the general population. 
Journal of Affective Disorders, 122(1-2), 86-95.

https://doi.org/10.1016/j.jad.2009.06.019

Masi, C. M., Chen, H. Y., Hawkley, L. C., \& Cacioppo, J. T. (2011). A meta-analysis of interventions to reduce loneliness. Personality and Social Psychology Review, 15(3), 219-266. https://doi.org/10.1177/1088868310377394

Matsuo, T., Kobayashi, D., Taki, F., Sakamoto, F., Uehara, Y., Mori, N., \& Fukui, T. (2020). Prevalence of health care worker nurnout during the coronavirus disease 2019 (COVID19) pandemic in Japan. JAMA Network Open, 3(8), e2017271. https://doi.org/10.1001/jamanetworkopen.2020.17271

Moreno, C., Wykes, T., Galderisi, S., Nordentoft, M., Crossley, N., Jones, N., Cannon, M., Correll, C. U., Byrne, L., Carr, S., Chen, E. Y. H., Gorwood, P., Johnson, S., Kärkkäinen, H., Krystal, J. H., Lee, J., Lieberman, J., López-Jaramillo, C., Männikkö, M., ... Arango, C. (2020). How mental health care should change as a consequence of the COVID-19 pandemic. The Lancet Psychiatry. https://doi.org/10.1016/S22150366(20)30307-2

Noguchi, K., Yamamoto, T., \& Tomida, K. (2020, August 20). Second wave of virus has now hit Japan, COVID-19 panel expert says. The Asahi Shimbun. http://www.asahi.com/ajw/articles/13652103

Ozcelik, H., \& Barsade, S. G. (2018). No employee an island: Workplace loneliness and job performance. Academy of Management Journal, 61(6), 2343-2366. https://doi.org/10.5465/amj.2015.1066

Raes, F., Pommier, E., Neff, K. D., \& Van Gucht, D. (2011). Construction and factorial validation of a short form of the Self-Compassion Scale. Clinical Psychology \& Psychotherapy, 18(3), 250-255. https://doi.org/10.1002/cpp.702

Sekhon, S. K., \& Srivastava, M. (2019). Conquering workplace loneliness Individual or 
organization accountability. Human Resource Management International Digest, 27(1), 1-3. https://doi.org/10.1108/HRMID-09-2018-0182

Sinclair, S., Kondejewski, J., Raffin-Bouchal, S., King-Shier, K. M., \& Singh, P. (2017). Can self-compassion promote healthcare provider well-being and compassionate care to others? Results of a systematic review. Applied Psychology: Health and Well-Being, 9(2), 168-206. https://doi.org/10.1111/aphw.12086

Snyder, C. R., Sympson, S. C., Ybasco, F. C., Borders, T. F., Babyak, M. A., \& Higgins, R. L. (1996). Development and validation of the State Hope Scale. Journal of Personality and Social Psychology, 70(2), 321-335. https://doi.org/10.1037/0022-3514.70.2.321 
Table 1. Participants Characteristics and Psychological Variables

\begin{tabular}{|c|c|c|c|c|}
\hline & \multicolumn{2}{|c|}{ Medical Workers $(n=142)$} & \multicolumn{2}{|c|}{ General Population $(n=138)$} \\
\hline & M & $\mathrm{SD}$ & M & SD \\
\hline \multicolumn{5}{|l|}{ Characteristics } \\
\hline Gender & \multicolumn{2}{|l|}{$\mathrm{F}=104, \mathrm{M}=38$} & \multicolumn{2}{|c|}{$\mathrm{F}=84, \mathrm{M}=54$} \\
\hline Age & 39.90 & 12.10 & $46.39 * *$ & 10.35 \\
\hline \multirow[t]{6}{*}{$\begin{array}{r}\text { Job Role / } \\
\text { Employment Status }\end{array}$} & Doctors & 28 & Full-Time Employees & 85 \\
\hline & Nurses & 34 & Part-Timers & 11 \\
\hline & Pharmacists & 29 & $\begin{array}{l}\text { Self-Employed incl. } \\
\text { Employers }\end{array}$ & 29 \\
\hline & Rehabilitation Workers & 27 & Homemakers & 5 \\
\hline & Social Workers & 5 & Unemployed & 2 \\
\hline & $\begin{array}{l}\text { Others incl. Nutritionists, } \\
\text { Radiographers }\end{array}$ & 19 & Others incl. Students & 6 \\
\hline \multicolumn{5}{|l|}{ Psychological Variables } \\
\hline Mental Health Problems & $3.27 * *$ & 2.78 & 2.37 & 2.31 \\
\hline Loneliness & $4.73 *$ & 1.7 & 4.33 & 1.56 \\
\hline Hope & 29.85 & 8.46 & $32.35 * *$ & 7.82 \\
\hline Self-Compassion & 3.13 & 0.58 & $3.34 * *$ & 0.61 \\
\hline
\end{tabular}


Table 2. Multiple Regression Analysis for Mental Health Problems

\begin{tabular}{|c|c|c|c|c|c|c|c|c|c|c|}
\hline & \multicolumn{5}{|c|}{ Medical Workers } & \multicolumn{5}{|c|}{ General Population } \\
\hline & B & $\mathrm{SE}_{\mathrm{B}}$ & $\beta$ & \multicolumn{2}{|c|}{$95.0 \% \mathrm{CI}$ for $\mathrm{B}$} & B & $\mathrm{SEB}_{\mathrm{B}}$ & $\beta$ & \multicolumn{2}{|c|}{$95.0 \% \mathrm{CI}$ for $\mathrm{B}$} \\
\hline Step 1 & & & & Lower & Upper & & & & Lower & Upper \\
\hline Gender & 0.03 & 0.17 & 0.02 & -0.31 & 0.37 & -0.18 & 0.14 & -0.11 & -0.45 & 0.09 \\
\hline Age & -0.01 & 0.01 & -0.13 & -0.02 & 0.00 & -0.01 & 0.01 & -0.12 & -0.02 & 0.00 \\
\hline Adj. $\mathrm{R}^{2}$ & \multicolumn{5}{|c|}{$0.30 \%$} & \multicolumn{5}{|c|}{$1 \%$} \\
\hline \multicolumn{11}{|l|}{ Step 2} \\
\hline Gender & 0.09 & 0.13 & 0.05 & -0.17 & 0.35 & -0.11 & 0.12 & -0.07 & -0.34 & 0.12 \\
\hline Age & 0.01 & 0.01 & 0.09 & 0.00 & 0.02 & 0.00 & 0.01 & -0.03 & -0.02 & 0.01 \\
\hline Loneliness & 0.92 & 0.17 & $0.39 * * *$ & 0.58 & 1.25 & 0.50 & 0.25 & $0.20 *$ & 0.01 & 0.99 \\
\hline Hope & -0.31 & 0.08 & $-0.28 * * *$ & -0.47 & -0.14 & -0.33 & 0.11 & $-0.27 * *$ & -0.54 & -0.11 \\
\hline Self-Compassion & -1.17 & 0.42 & $-0.22 * *$ & -2.01 & -0.33 & -1.06 & 0.49 & $-0.21 *$ & -2.04 & -0.09 \\
\hline$\Delta \operatorname{Adj} . \mathrm{R}^{2}$ & \multicolumn{5}{|c|}{$44 \%$} & \multicolumn{5}{|c|}{$30 \%$} \\
\hline
\end{tabular}

Outcome variable $=$ Mental Health Problems. $\mathrm{B}=$ Unstandardized Coefficients, $\mathrm{SE}_{\mathrm{B}}=$ Standard Error of the Coefficient, $\beta=$ Standardized Coefficients. * $p<0.05 ; * * p<0.01 ; * * * p<0.001$ 